Advances in Radio Science (2003) 1: 53-56

(C) Copernicus $\mathrm{GmbH} 2003$

\title{
Achievable field strength in reverberation chambers
}

\author{
N. Eulig ${ }^{1}$, A. Enders ${ }^{1}$, H. G. Krauthäuser ${ }^{2}$, and J. Nitsch ${ }^{2}$ \\ ${ }^{1}$ Technische Universitt Braunschweig, Institut fr EMV, Schleinitzstr. 23, D-38106 Braunschweig, Germany \\ ${ }^{2}$ Universitt Magdeburg, Institut für Grundlagen der Elektrotechnik und Elektromagnetische Verträglichkeit, P.O. Box 4120, \\ D-39016 Magdeburg, Germany
}

\begin{abstract}
Feldvariable Kammern (FVK, engl.: modestirred-chamber) werden unter anderem für EMV-Störfestigkeitsprüfungen verwendet. Ein häufig genanntes Argument, das die Einführung dieser Kammern als normgerechte Prüfumgebung vorantreiben soll, ist eine hohe Feldstärke, die im Vergleich zu anderen Testumgebungen mit relativ moderaten HF-Leistungen erreicht werden kann. Besonders für sicherheitskritische Geräte, wie Komponenten aus der Avionik- oder KFZ-Industrie, sind heutzutage Testfeldstärken von mehreren $100 \mathrm{~V} / \mathrm{m}$ notwendig. Derart hohe Feldstärken können in Umgebungen, die ein ebenes Wellenfeld erzeugen oder nachbilden, nur mit großen HFLeistungen generiert werden. Durch die Resonanzeigenschaften einer FVK können demgegenüber mit sehr viel weniger Leistung und damit Verstärkeraufwand vergleichbare Werte der Feldstärke erzeugt werden. Allerdings sinkt mit zunehmendem Volumen die erreichbare Feldstärke bei gleicher Speiseleistung. Idealerweise sollen Feldvariable Kammern bei möglichst niedrigen Frequenzen für EMVTests nutzbar sein, was jedoch ein großes Kammervolumen erfordert. Das Problem, bei niedrigen Frequenzen hohe Feldstärken erzeugen zu können, relativiert deshalb den Vorteil von FVKn gegenüber bekannten Testumgebungen bei niedrigen Testfrequenzen.

Der Posterbeitrag erläutert, welche Feldstärken in verschieden großen Feldvariablen Kammern beim Einspeisen einer bestimmten hochfrequenten Leistung erreicht werden können. Anhand dieser Ergebnisse wird aufgezeigt, oberhalb welcher Grenzfrequenz eine Anwendung von FVKn nur sinnvoll erscheint.
\end{abstract}

Mode-stirred chambers (MSCs) can be used for radiated immunity tests in EMC testing. Advantageous compared to conventional test methods is the high field strength which can here be generated with less RF-Power. This point is often the main argument for pushing the standardization of

Correspondence to: N. Eulig

(n.eulig@tu-bs.de)
MSCs as an other EMC testing environment. Especially for safety-critical electronic equipment like avionic or automotive systems, immunity tests with field strengths of several $100 \mathrm{~V} / \mathrm{m}$ are necessary. Such high field strengths can only be generated with substantial RF power and therefore expensive amplifiers if the test is performed in an environment with plane waves. Due to resonance effects in mode-stirred chambers, comparable values of the field strength can there be obtained with significantly less power. In these chambers the field strength declines with increasing volume for a constant input power. As an ideal testing environment a mode-stirred chamber should also work at low frequencies which requires a large volume, however. Hence there is a contradiction between generating high level field strengths on the one hand and obtaining a lowest usable frequency of several $10 \mathrm{MHz}$ on the other. This relativizes the advantage of generating high field strengths with less power if the chamber is supposed to work down to low frequencies.

This article deals with the field strengths that can be obtained in mode-stirred chambers with a certain size. Data of different mode-stirred chambers are compared. From this a frequency limit can be derived, above which the use a mode-stirred chamber for achieving high field strengths seems meaningful only.

\section{Mode of operation}

Reverberation chambers are often regarded as cost-effective facilities for EMC testing. A strong point seems to be the high field strength which can be generated by significantly less power compared to anechoic rooms. In this poster the limit of this effect due to intrinsic loss mechanisms of reverberation chambers will be shown.

A reverberation chamber consists of a shielded room. Its dimensions are large with respect of the lowest used testing frequency. These rooms are equipped with a metallic rotatable tuner. This tuner generates a very high number of different electrical field patterns by changing its position while 


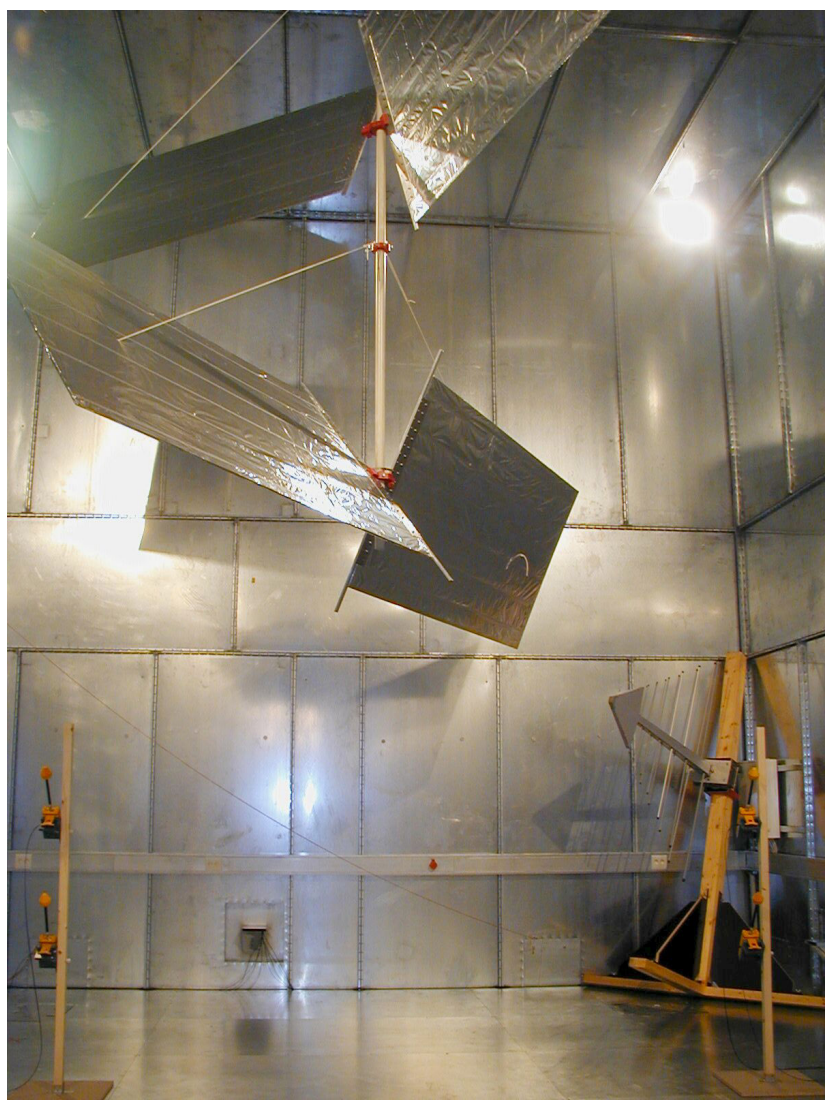

Fig. 1. View inside a mode-stirred chamber. The rotatable tuner to the top has a diameter of approx. $5 \mathrm{~m}$.

the frequency remains constant. As a consequence, the maxima of the cavities resonant modes change their spatial position. In this way the equipment under test (EUT) is exposed to a field which has the same maximum value within approximately $2-4 \mathrm{~dB}$ at every point of the EUT within one complete revolution of the tuner. Because of the low number of eigenmodes in the cavity directly above the first resonance frequency the effect of moving the maxima by the tuner works well only if a certain frequency is exceeded. This frequency is called LUF (lowest usable frequency). It is dependent on the shape and size of the cavity and wellness of the tuner. Therefore, it is an individual characteristic of every reverberation chamber and can be estimated only prior to the construction of any chamber. A more accurate value can be determined on the basis of different measurements in the chamber as an empirical value.

\section{Loss mechanisms, cavity quality factor $Q$ and cham- ber gain $G$}

The loss mechanism of an ideal empty chamber is mainly determined by the wall material. Especially if the frequency is high compared to the LUF the loss induced by a matched transmitting or receiving antenna can be neglected and the power transmitted into the chamber will be converted into

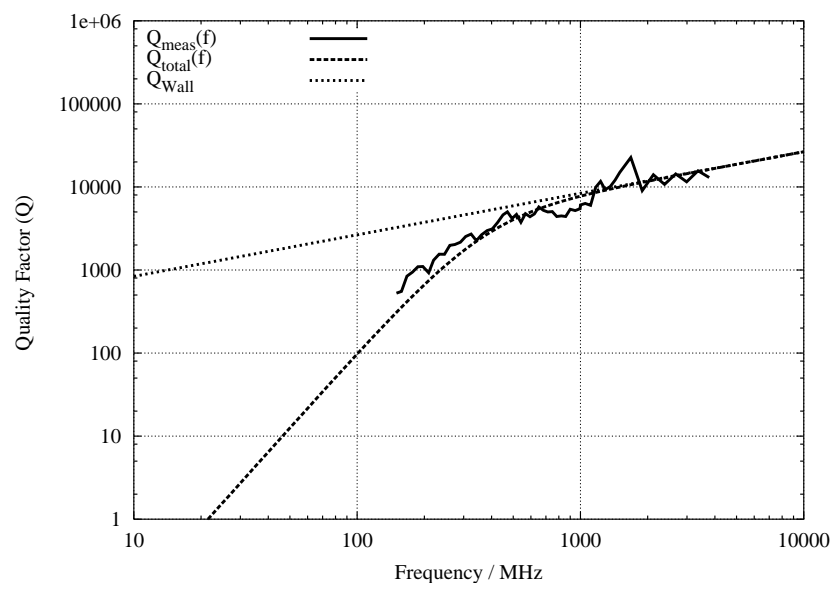

Fig. 2. Typical distribution of $Q$ in a reverberation chamber with a dimension of $8 \mathrm{~m} \times 6 \mathrm{~m} \times 3.5 \mathrm{~m}$. The wall material is assumed to have a conductivity of $\sigma_{w}=10^{6} \mathrm{~S} / \mathrm{m}$. Considered are losses in the walls and in one matched antenna as well as a factor of 0.1 for fitting the curves to the measured data.

heat in the walls. The diagram in Fig. 2 shows the behaviour of $Q$ versus $\mathrm{f}$ under consideration of the antenna loss for one antenna and the contribution of the walls $Q_{w}$. This clarifies that at high frequencies the quality factor $Q$ of an ideal chamber is mainly determined by the material properties of the walls. It can be shown that $Q$ is a function of the chambers volume $V$, the surface $S$ and the square root of the used frequency f. For the diagram in Fig. 2 a conductivity of $\sigma_{w}=10^{6} \mathrm{~S} / \mathrm{m}$ and a chamber size of $8 \mathrm{~m} \times 6 \mathrm{~m} \times 3.5 \mathrm{~m}$ is assumed. For fitting the curve of the total quality factor to the measured values, a factor of 0.1 was multiplied to $Q_{\text {total }}$.

If a reverberation chamber is used as a testing environment there will be additional losses caused by the absorption of the EUT placed into the chamber. This effect will decrease $Q$ and consequently the electrical field strength if the transmitted power remains constant. Therefore this effect has to be compensated for by increasing the transmitted power into the chamber. However, in this consideration an empty chamber is regarded.

\section{Distribution of the electrical field strength}

In general the field strength depends on frequency. This is due to the variation of the absorption with frequency or chamber quality $Q$, respectively. Remember that with increasing frequency the power dissipated in the walls raises, too. In the lower frequency range the dominant absorption mechanism is caused by the antenna. The diagram in Fig. 3 shows the distribution of $E$ of an ideal chamber with the parameters given above. With increasing frequency the electrical field rises at first and then declines steadily due to higher absorption of the walls at higher frequencies.

For the investigation of the behaviour of $E$ versus the surface area of different chambers it is necessary to compare the data at a fixed frequency. Therefore it should be kept in 
Table 1. Different chambers and their surface area compared with the associated lowest usable frequency

\begin{tabular}{cccc}
\hline Chamber & Volume $/ \mathrm{m}^{3}$ & $f_{110} / \mathrm{MHz}$ & $\mathrm{LUF} / \mathrm{MHz}$ (empirical value) \\
\hline A & 17 & 71 & 300 \\
B & 29 & 69 & 300 \\
D & 38 & 58 & 300 \\
C & 80 & 43 & 150 \\
E & 107 & 38 & 150 \\
F & 170 & 31 & 150 \\
G & 290 & 24 & 100 \\
H & 594 & 24 & 80 \\
J & 1360 & 15 & $30 \ldots 50$ \\
\hline
\end{tabular}

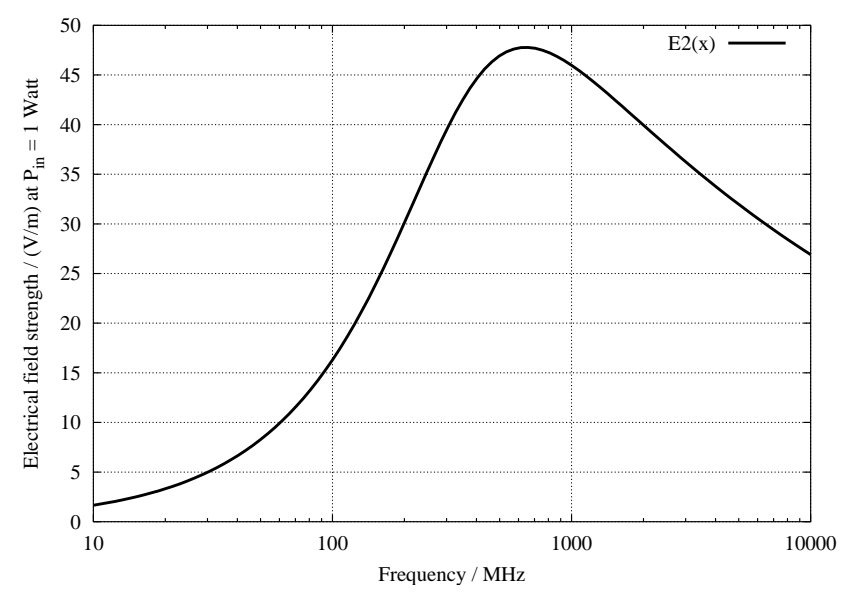

Fig. 3. Typical distribution of the electrical field strength in a reverberation chamber. The data shown are based on the $Q$-values shown in Fig. 2.

mind that in this investigation the estimated field strength for a specific surface area is given only at a frequency of $1 \mathrm{GHz}$. At higher frequencies lower values of $E$ are expected.

\section{Electrical field strength as a function of surface area}

The ratio between the electrical field strength squared $E^{2}$ and transmitted power $P_{n e t}$ is proportional to the chamber gain $G$. This gain is physically determined by the wall material and the surface area $S$ as well as the used frequency. From that we can get a relationship between $E$ and $S$. Provided that the conductivity of the wall material is constant this results in the expression:

$E \propto \frac{1}{\sqrt{S}}$

For comparing different chambers it is important that the wall materials have the same conductivity and therefore the skin depth is nearly the same. Otherwise the compared field strengths may show greater variations than expected.

The data presented here is based on a frequency of $1 \mathrm{GHz}$ since that at this frequency data were available for most of

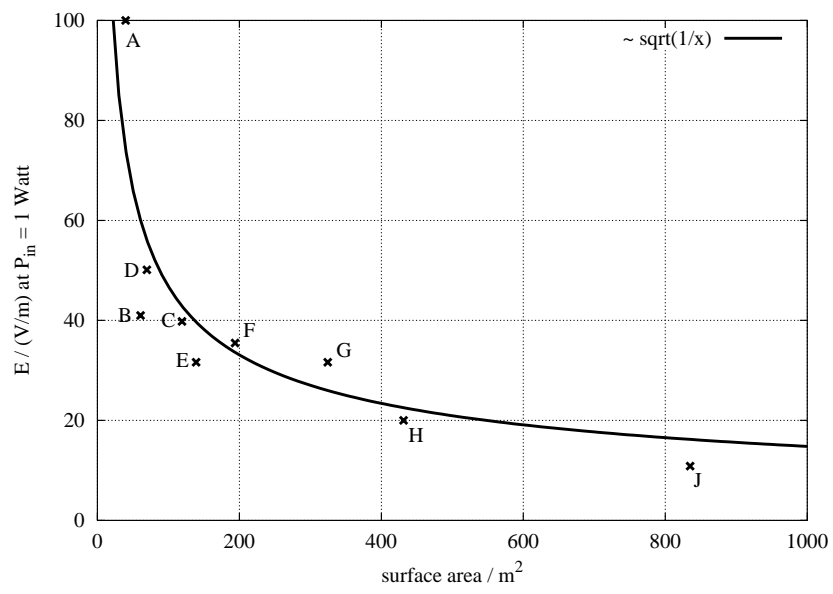

Fig. 4. Dependency of the electrical field strength vs. surface area in a reverberation chamber at a frequency of $1 \mathrm{GHz}$.

the chambers. Figure 4 shows that the electrical field declines with increasing surface area of a chamber if the input power remains constant. The curve is a fit based on the measured data and has a distribution proportional to $\sqrt{1 / S}$.

\section{Error sources}

The investigated chambers may have different wall conductivities. Therefore the generated field strength will differ even if the chamber size is nearly the same.

Sometimes it was not explicitly mentioned if $P_{n e t}$ or $P_{i n}$ was used to normalize the electrical field strength. For $P_{n e t} \neq P_{i n}$ this could result in slightly different field strengths dependent on the antennas used for transmission.

There is not always measured $E$-field data available, instead the used values based on statistical estimations depend on the number of measured samples or tuner steps, respectively. This may cause variations of several $\mathrm{dB}$. 


\section{Discussion}

A large reverberation chamber is needed to achieve a low LUF. Opposed is the effect that with increasing surface area the obtained field strength for a constant input power at a fixed frequency declines due to higher overall losses in the walls. This leads to a contradiction of generating high field strengths with less power and simultaneously desiring a low LUF.

For the construction of a reverberation chamber it is necessary to make a trade off between a low start frequency and generating high field strengths. Therefore it may be more cost-effective to use an anechoic chamber for the low frequency range especially if the needed measurement time is taken into consideration. The time required for measurements in reverberation chambers near by the LUF takes much more time compared to measurements conducted in anechoic rooms, as described in the reference.

\section{References}

EMV-Fahrzeugprfungen mit Feldvariabler Kammer, GMMFachbericht Nr. 35, Elektromagnetische Verträglichkeit in der KFZ-Technik, VDE-Verlag, Berlin, ISBN 3-8007-2633-5, 2001. 